\title{
Preliminary findings on the reliability and validity of the Cantonese Birmingham Cognitive Screen in patients with acute ischemic stroke
}

This article was published in the following Dove Press journal:

Neuropsychiatric Disease and Treatment

16 September 2015

Number of times this article has been viewed

\author{
Xiaoping Pan ${ }^{1, *}$ \\ Haobo Chen ${ }^{1,2, *}$ \\ Wai-Ling Bickerton ${ }^{2}$ \\ Johnny King Lam Lau ${ }^{2}$ \\ Anthony Pak Hin Kong ${ }^{3}$ \\ Pia Rotshtein ${ }^{2}$ \\ Aihua Guo' \\ Jianxi $\mathrm{Hu}^{\prime}$ \\ Glyn W Humphreys ${ }^{4}$ \\ 'Department of Neurology, \\ Guangzhou First People's \\ Hospital, Guangzhou Medical \\ University, Guangzhou, People's \\ Republic of China; ${ }^{2}$ School \\ of Psychology, University of \\ Birmingham, Birmingham, UK; \\ ${ }^{3}$ Department of Communication \\ Sciences and Disorders, University \\ of Central Florida, Orlando, FL, \\ USA; ${ }^{4}$ Department of Experimental \\ Psychology, University of Oxford, \\ Oxford, UK \\ *These authors contributed equally \\ to this work
}

Correspondence: Glyn W Humphreys Department of Experimental Psychology, University of Oxford, South Parks Road, Oxford OXI 3UD, UK

Email glyn.humphreys@psy.ox.ac.uk

Xiaoping Pan

Department of Neurology, Guangzhou

First People's Hospital, Guangzhou

Medical University, 602 Renminbei Road,

Guangzhou 510000, People's Republic

of China

Tel +86 I38 088। 0008

Email qpanxp@।63.com
Background: There are no currently effective cognitive assessment tools for patients who have suffered stroke in the People's Republic of China. The Birmingham Cognitive Screen (BCoS) has been shown to be a promising tool for revealing patients' poststroke cognitive deficits in specific domains, which facilitates more individually designed rehabilitation in the long run. Hence we examined the reliability and validity of a Cantonese version $\mathrm{BCoS}$ in patients with acute ischemic stroke, in Guangzhou.

Method: A total of 98 patients with acute ischemic stroke were assessed with the Cantonese version of the $\mathrm{BCoS}$, and an additional 133 healthy individuals were recruited as controls. Apart from the $\mathrm{BCoS}$, the patients also completed a number of external cognitive tests, including the Montreal Cognitive Assessment Test (MoCA), Mini Mental State Examination (MMSE), Albert's cancellation test, the Rey-Osterrieth Complex Figure Test, and six gesture matching tasks. Cutoff scores for failing each subtest, ie, deficits, were computed based on the performance of the controls. The validity and reliability of the Cantonese $\mathrm{BCoS}$ were examined, as well as interrater and test-retest reliability. We also compared the proportions of cases being classified as deficits in controlled attention, memory, character writing, and praxis, between patients with and without spoken language impairment.

Results: Analyses showed high test-retest reliability and agreement across independent raters on the qualitative aspects of measurement. Significant correlations were observed between the subtests of the Cantonese $\mathrm{BCoS}$ and the other external cognitive tests, providing evidence for convergent validity of the Cantonese $\mathrm{BCoS}$. The screen was also able to generate measures of cognitive functions that were relatively uncontaminated by the presence of aphasia.

Conclusion: This study suggests good reliability and validity of the Cantonese version of the $\mathrm{BCoS}$. The Cantonese $\mathrm{BCoS}$ is a very promising tool for the detection of cognitive problems in Cantonese speakers.

Keywords: cerebral infarction, cognitive impairment, neuropsychological testing, validation test, reliability test, Cantonese speakers

\section{Introduction}

There is a high incidence of stroke in the People's Republic of China, with the age-standardized annual incidence of first stroke among Chinese individuals aged 45-74 years falling between 205 and 584 per 100,000. ${ }^{1}$ Stroke is a common cause of cognitive impairment. ${ }^{2}$ Prior studies have shown that between $44 \%$ and $74 \%$ of patients present with some degree of cognitive disturbance when tested 6 months after their stroke - with the incidence dependent on the type of cognitive problem and the form of measurement. ${ }^{3}$ Since early intervention can improve outcome, ${ }^{4,5}$ it is important to test stroke patients and to detect cognitive impairments in the subacute stage. 
The Mini Mental State Examination (MMSE) ${ }^{6}$ and the Montreal Cognitive Assessment Test (MoCA) ${ }^{7}$ are probably the most commonly used cognitive screening tests in the People's Republic of China, if not worldwide. However, the MMSE lacks sensitivity to detect patients with mild symptoms, especially those with visuospatial and executive function impairments. ${ }^{8}$ The MoCA, though more sensitive than the MMSE, ${ }^{9}$ remains limited. For example, being developed for dementia, the MoCA is not "tuned" to detect some of the common cognitive problems after stroke - notably visuospatial neglect and apraxia. ${ }^{10-13}$ Moreover, both the MMSE and the MoCA are highly verbal screens, with the majority of tests requiring good verbal abilities. This means that patients with aphasia found after stroke can fail the tests for reasons to do with language impairments and not the putative factors being tested (eg, memory or attention). There is also a lack of specificity in assigning a problem to a specific cognitive function. These screens typically return an overall score, which cannot be easily used to direct treatment, as treatment needs to target the specific cognitive problem (eg, therapy for spatial neglect differs from that for apraxia).

The Birmingham Cognitive Screen (BCoS) battery ${ }^{14}$ is a new instrument that was developed to screen individuals for cognitive problems after a stroke and to generate a cognitive profile across a range of cognitive domains (Attention and Executive Function; Language; Memory; Number Skills; and Praxis). Importantly, the test is designed to maximize inclusion of stroke patients, while generating test results that are uncontaminated by the co-occurrence of language or spatial attention problems, which can otherwise have a contaminating impact on performance. The test is made "aphasia friendly" by including short, high-frequency words, whenever possible, when language is not directly assessed and by incorporating forced-choice response options (so aphasic patients can point even when they cannot make a verbal response). The tests are "neglect friendly" in their spatial design (the stimuli are vertically aligned in the midline, in order to avoid interference of neglect) and the use of multimodal exposures.

\section{Method}

\section{Subjects}

The participants were 98 patients with ischemic stroke, from the Neurological Department of Guangzhou First People's Hospital, and 133 healthy controls. The control participants were recruited from the physical examination center in the hospital, from among relatives of the patients, and from among residents of several old peoples' communities in Guangzhou. All the participants were native Cantonese speakers.
All the control participants were aged 50 years or above, without a history of brain lesion and without complaint of memory loss. Participants who had a MoCA score less than 22 were excluded from the control group..$^{15,16}$

Patients were recruited between July 2013 and March 2014.

The inclusion criteria for the patient group were as follows:

1. Aged 50 years and above

2. Within 2 weeks of a confirmed stroke and without a prior history of brain lesion; the patient was judged by the clinical team to be able to concentrate for at least 45 minutes, to enable the tests to be administered

3. The patient consented to testing and signed the consent document.

The exclusion criteria were:

1. Past history of cognitive impairment and brain lesion including a history of stroke

2. The presence of chronic heart failure, anemia, or other diseases that may lead to cognitive impairment

3. Inability to concentrate for at least 45 minutes.

The study was approved by the local research ethics committee, and participants gave informed, written consent.

\section{Cultural and linguistic modifications of $\mathrm{BCoS}$}

The validity and reliability of the $\mathrm{BCoS}$ has previously been established in English (in the UK). ${ }^{17}$ In the present paper, we report on the validity and reliability of the Cantonese version of the screen. For this version, four specific cultural and linguistic modifications were made.

\section{Picture naming}

Some of the items were identified as being culturally inappropriate in the People's Republic of China, and these were replaced (eg, the picture of a colander was rejected, as colanders are not standardly used in Chinese cooking; this was replaced with a picture of a spatula).

\section{Sentence reading and nonword reading}

Here, we define a "regular" character as one being "regularconsistent" while an "exception" character as one being "irregular-inconsistent". Both 'regularity' and 'consistency' are often used to describe mapping between orthography and phonology.$^{18}$ Broadly speaking, a written word (ie, a character in Chinese writing) is regular if its pronunciation follows the grapheme-to-phoneme correspondence rules of the written language (eg, "doctor" in English); ${ }^{19}$ and a word/character is an exception if its pronunciation deviates 
from those rules (eg, "daughter" in English). Consistency is described with respect to the orthographic body and the phonological rime. A consistent word/character (eg, wade in English) is one that has a word-body (-ade) pronounced in the same way for the entire set of orthographic neighbors (eg, spade, jade, made). An inconsistent word/character (e.g., wave in English) has among its neighbors at least one exception word (eg, have).

In the Cantonese sentence reading task, we included only 'regular' characters which are also 'consistent', that is, those having a consistency value of $>80 \%$ (ie, more than $80 \%$ of its orthographic neighbors are pronounced in the same way as the chosen word). With regard to the 'exception' characters, we included only 'irregular' characters which are also 'inconsistent', that is, those having a consistent value of $<20 \%$ (ie, less than $20 \%$ of its orthographic neighbors are pronounced in the same way as it is). On the whole, all items chosen have a frequency of $>200$ (in millions) documented in Leung et al (unpublished database, 2010).

\section{Gesture production and gesture recognition}

Some of the gestures were replaced to fit with Chinese culture and daily habits (eg, the gesture of hitchhiking was rejected because this activity is not common in the People's Republic of China; this item was then replaced with a gesture of rubbing one's thumb and forefinger together to indicate money).

\section{Word writing}

Chinese character writing is an equivalent task to (real) word writing in the original English version. During the task, a common, familiar word (eg, “眼睛”, the word for "eye" in Chinese) consisting of the target character (eg, " 眼”, /ngaan5/) and another character that often coappears (eg, “睛”, /zing1/) is voiced out, although the participant is only required to produce the target character in the written response. There are four items in this test, half of which are concrete characters (representing real objects), and the other half are abstract (representing concepts). Within each category, one item is a regular character, while the other is an exception character. The characters were taken from The Hong Kong, Mainland China and Taiwan: Chinese Character Frequency list (http://humanum.arts.cuhk.edu.hk/Lexis/chifreq/), with a word frequency ranging between 5000/663461 and $11115 / 663461$. The 15 characters are controlled for the six tones in Cantonese, part-of-speech, number of strokes, and phonetic structures ("CV", "CVV", and "CVC"), ${ }^{20}$ with minimal repetition of the same onsets and rimes. Disyllabic and trisyllabic word items were created by randomly combining the 15 characters. Character combination was subsequently verified to ensure that characters do not exist together in any known words in Cantonese. Regarding nonword writing, a test of writing Chinese pseudocharacters (or nonwords) is not available in the Cantonese version, as it is impossible to achieve in the logographic Chinese writing system.

\section{Tests}

A forward-backward translation of the BCoS was conducted. The battery was first translated from English into Cantonese by author AK. Author JL then translated the Cantonese version back into English. Any disagreements $(<5 \%$ out of all translated items) were subsequently resolved to maintain the integrity, consistency, and accuracy of the translation. Note that some items in subtests were replaced by stimuli with cultural and linguistic modifications (as described above); all other items were directly adopted and translated from the English version.

All the patients were tested on the Cantonese version of the $\mathrm{BCoS}$, the MoCA, the MMSE, Albert's test of neglect, ${ }^{21}$ the Rey-Osterrieth Complex Figure Test, ${ }^{22}$ and six gesture matching tasks from Goldenberg. ${ }^{23}$ The MoCA and MMSE were used to validate assessments of language, number processing, and memory; the Rey-Osterrieth Complex Figure Test was used to validate complex figure copying; Albert's test was used to validate the BCoS measure of neglect (Apple cancellation); and Goldenberg's tasks were employed to validate the praxis tests in the $\mathrm{BCoS}$. All the participants were randomly assessed by one of four testers in our study. All the testers were doctors in the Neurological Department, and all were trained in test administration by the research teams at Birmingham and Oxford Universities (UK). The interrater reliability was shown in the results.

Subsets of the controls and the patients were retested on a second occasion to establish test-retest reliability. The subject's identity (as a control or patient) was not blind to the testers, as it is almost impossible to blind a tester to the presence of a hemiplegia or a major cognitive deficit in a stroke patient. Also, scores requiring qualitative judgments of performance were assessed by two other testers in order to evaluate interrater reliability. The testers were blind to each other's score.

\section{Statistical analysis}

Demographic data were compared between the control and patient groups using an independent $t$-test. Cutoffs were set at the 5th percentile, for scores indicating high ability, and at the 95th percentile, for scores indicating difficulties, and were smoothed across age groups. Pearson's correlation tests 
were used to test the test-retest reliability and convergent validity. The interrater reliability was addressed by calculating interclass correlations among the scores of three parallel ratings of the Cantonese version $\mathrm{BCoS}$.

\section{Results}

\section{General condition}

A total of 133 healthy participants were assessed, with 51 males and 82 females. The average age of these controls was $65.70 \pm 8.99$ years, and the average years of education was $9.12 \pm 4.20$. Ninety-eight stroke patients participated, including 57 males and 41 females. Considering the decay of cognitive ability along with age growth, participants were divided into two age groups. Within each of the age groups, the patients and controls did not differ in either their age or the level of education (both $P>0.05$ ) (Table S1).

There were 98 patients in our study, including 39 patients with left hemispheric lesion, 36 with right hemispheric lesion, five with bilateral hemispheric lesion, and 15 with brainstem and cerebellum lesion. According to the TOAST classification, ${ }^{24}$ there were 30 patients with large-artery atherosclerosis, seven with cardioembolism, 57 with small-artery occlusion, and four with undetermined etiology. The average National Institutes of Health Stroke Scale (NIHSS) score of the patient group was $2.355 \pm 2.45$ (ranged from 0 to 15).

\section{Normative data}

The standardization sample for BCOS was divided into two age groups: $50-69$ years and $\geq 70$ years. The mean score and 5th and 95th percentile cutoffs are presented in Table 1. The test labels presented in the table were all taken from the $\mathrm{BCoS}{ }^{24}$ Subtests were divided into their respective domains.

Cutoff scores were set at the 5th percentile for scores indicating high ability and the 95 th percentile for scores indicating difficulties, smoothed across age groups. The cutoffs were set at the 2.5th and 97.5th percentiles for subtests that had two tails (eg, the spatial asymmetry scores, which could be positive or negative).

Table 2 presents the numbers of stroke patients who were impaired on the tests, based on the cutoffs given in Table 1.

The results are consistent with considerable numbers of patients being impaired relative to our cutoffs - up to $40 \%$ of the patients had some impairment in complex figure copy, and about $20 \%$ had problems in aspects of controlled attention (eg, auditory attention accuracy). Note that these particular tests are relatively unbound by culture.

\section{Reliability studies}

\section{Test-retest reliability}

The test-retest assessments were performed on the eleven controls, who were examined with a test-retest interval ranging from 122 to 330 days ( $205 \pm 95.93$ days). The average age of these participants was 63.8 years ( $\mathrm{SD}=7.99$ years), and they had received an average of 10.5 years of education ( $\mathrm{SD}=3.39$ years). There were five males and six females. In addition, test-retest resampling was also carried out on 15 stroke patients. The average age of the stroke patients was 64.5 years ( $\mathrm{SD}=6.66$ years). There were 12 males and three females, and they had received an average 9 years of education ( $\mathrm{SD}=3.17$ years). The test-retest interval in this case ranged from 102 to 191 days (144.2 25.61 days).

The data were analyzed in two ways. First, correlations were conducted between the test and retest scores, pooling the data across patients and controls to maximize power. Tests were not included here, where the controls were uniformly at ceiling. This meant, too, that for the measure of spatial attention, we took only the overall score and not the asymmetry scores (since controls showed no spatial asymmetries). The correlation results are shown in Table 3.

There were reliable correlations across all the subtests that remained after filtering for ceiling effects. These correlations were not solely due to the contrast between patients and controls, and were apparent even when each group was considered alone.

In the second analysis, we assessed performance differences at times 1 and 2, using the Wilcoxon signed rank test. As for the correlation analyses, the assessments were performed only for tests where the controls did not score at ceiling and then, pooling the data across the patients and the controls (Tables S2, S3, and S4). In nearly all cases, there were no differences between performance on the two test occasions. The exceptions to this were for the recognition test and the second recall task, where performance improved on the second test occasion. This held for the data for the patients when they were considered alone too $(P=0.026$ [recognition test] and $P=0.064$ [second recall test]).

\section{Interrater reliability}

There are five tests in the $\mathrm{BCoS}$ where scoring requires qualitative judgments of performance: the sentence construction task, multistep object use tasks, gesture production, imitation, and figure copying. To assess interrater reliability, three independent raters scored the performance of ten ischemic stroke patients, and interclass correlations (ICC) between the scores of the three parallel ratings of the $\mathrm{BCoS}$ subtests 
Table I Mean scores, and 5th and 95th percentiles across the two age groups of healthy participants

\begin{tabular}{|c|c|c|c|c|c|c|}
\hline & \multicolumn{3}{|c|}{$50-69$ years $N=94$} & \multicolumn{3}{|c|}{$\geq 70$ years $N=39$} \\
\hline & $\begin{array}{l}\text { Score } \\
\text { range }\end{array}$ & Mean & $\begin{array}{l}\text { 5th or } 95 \text { th } \\
\text { percentile }\end{array}$ & $\begin{array}{l}\text { Score } \\
\text { range }\end{array}$ & Mean & $\begin{array}{l}\text { 5th or 95th } \\
\text { percentile }\end{array}$ \\
\hline \multicolumn{7}{|l|}{ Attention-spatial } \\
\hline Apple cancellation (accuracy) & $0-50$ & 46.6 & 42 & $0-50$ & 45.79 & 39 \\
\hline Asymmetry (allocentric) (R, L) & $0-20$ & 0.02 & 0,1 & $0-20$ & -0.21 & $-2,1$ \\
\hline Asymmetry (egocentric) (R, L) & $0-20$ & 0.29 & $-3,3$ & $0-20$ & -0.13 & $-3,4$ \\
\hline Left visual unilateral & $0-4$ & 3.97 & 4 & $0-4$ & 4 & 4 \\
\hline Right visual unilateral & $0-4$ & 3.98 & 4 & $0-4$ & 4 & 4 \\
\hline Left visual bilateral & $0-8$ & 7.99 & 8 & $0-8$ & 8 & 8 \\
\hline Right visual bilateral & $0-8$ & 8 & 8 & $0-8$ & 7.97 & 8 \\
\hline Left tactile unilateral & $0-4$ & 4 & 4 & $0-4$ & 3.95 & 3 \\
\hline Right tactile unilateral & $0-4$ & 3.98 & 4 & $0-4$ & 3.97 & 3 \\
\hline Left tactile bilateral & $0-8$ & 7.96 & 8 & $0-8$ & 7.97 & 8 \\
\hline Right tactile bilateral & $0-8$ & 7.97 & 8 & $0-8$ & 7.97 & 8 \\
\hline \multicolumn{7}{|l|}{ Attention-controlled } \\
\hline Auditory attention accuracy & $0-54$ & 50.82 & 39 & $0-54$ & 48.92 & 33 \\
\hline Auditory attention practice & $\mathrm{I}-3$ & 1.09 & $\mathrm{I}$ & $\mathrm{I}-3$ & 1.29 & 1 \\
\hline Auditory attention word recall & $0-3$ & 2.83 & 2 & $0-3$ & 2.68 & 2 \\
\hline Sustained attention index & & 0.50 & $-2,4$ & & 0.08 & $-4,3$ \\
\hline Rule finding and set shifting accuracy & $0-18$ & 11.96 & 6 & $0-18$ & 11.13 & 3 \\
\hline Rule finding-rules found & $0-3$ & 2.21 & 0 & $0-3$ & 2.03 & 0 \\
\hline \multicolumn{7}{|l|}{ Language-spoken } \\
\hline Instruction comprehension & $1-3$ & 3 & 3 & $1-3$ & 2.84 & 2 \\
\hline Picture naming & $1-14$ & 13.29 & 11 & $1-14$ & 12.03 & 8 \\
\hline Sentence construction & $0-8$ & 7.80 & 7 & $0-8$ & 7.82 & 6 \\
\hline \multicolumn{7}{|l|}{ Language-written } \\
\hline Nonword reading-accuracy & $0-6$ & 5.84 & 5 & $0-6$ & 5.89 & 5 \\
\hline Sentence reading-accuracy & $0-40$ & 39.27 & 37 & $0-40$ & 39.26 & 34 \\
\hline Character writing & $0-4$ & 3.38 & I & $0-4$ & 3.19 & I \\
\hline \multicolumn{7}{|l|}{ Memory-orientation } \\
\hline Personal & $0-8$ & 7.94 & 7 & $0-8$ & 7.90 & 7 \\
\hline Time and space & $0-6$ & 5.99 & 6 & $0-6$ & 5.87 & 5 \\
\hline \multicolumn{7}{|l|}{ Memory-episodic } \\
\hline Story free-recall I & $0-15$ & 7.03 & 4 & $0-15$ & 5.64 & 2.5 \\
\hline Story recognition I & $0-15$ & 12.45 & 9 & $0-15$ & 11.62 & 8 \\
\hline Story free-recall 2 & $0-15$ & 9.46 & 5.5 & $0-15$ & 7.55 & 3 \\
\hline Story recognition 2 & $0-15$ & 14.22 & 13 & $0-15$ & 13.46 & 9 \\
\hline Task-recognition & $0-10$ & 9.43 & 8 & $0-10$ & 8.92 & 7 \\
\hline \multicolumn{7}{|l|}{ Number } \\
\hline Reading & $0-9$ & 8.78 & 8 & $0-9$ & 8.42 & 7 \\
\hline Writing & $0-5$ & 4.68 & 3 & $0-5$ & 4.46 & 2 \\
\hline Calculation & $0-4$ & 3.71 & 2 & $0-4$ & 3.47 & 2 \\
\hline \multicolumn{7}{|l|}{ Praxis-action } \\
\hline Figure copy & $0-47$ & 43.24 & 37 & $0-47$ & 41.92 & 34 \\
\hline Multistep object use & $0-12$ & 11.86 & 11 & $0-12$ & 11.76 & 11 \\
\hline Gesture production & $0-12$ & 11.20 & 9 & $0-12$ & 10.45 & 7 \\
\hline Gesture recognition & $0-6$ & 5.96 & 6 & $0-6$ & 5.92 & 6 \\
\hline Imitation & $0-12$ & 10.30 & 6 & $0-12$ & 9.47 & 5 \\
\hline
\end{tabular}

Abbreviations: R, right; L, left.

were calculated. Results showed that there was no significant difference between the raters' judgments in respect of these qualitative assessments (Table S5).

\section{Convergent validity}

The different subtests of the BCOS were validated against existing measures chosen to index the same underlying cognitive function. The standard tests selected for each
BCoS subtest are listed in Table 4, along with the number of participants (patients and controls) for which data were collected and correlated. The data reported in Table 4 cover both patients and controls (pooled results) and indicate reliable correlations across all the selected tasks. This did not reflect purely the difference between the patients and the controls, and similar results occurred for just the patients considered alone (Table S6). 
Table 2 Numbers of patients who were impaired on BCoS subtests

\begin{tabular}{|c|c|c|c|c|}
\hline & \multicolumn{2}{|l|}{$50-69$ years } & \multicolumn{2}{|l|}{$\geq 70$ years } \\
\hline & Frequency & $\%$ & Frequency & $\%$ \\
\hline \multicolumn{5}{|l|}{ Attention and executive function } \\
\hline \multicolumn{5}{|l|}{ Spatial } \\
\hline Apple cancellation (accuracy) & $10 / 49$ & 20.4 & $13 / 47$ & 27.7 \\
\hline Asymmetry (allocentric) (R, L) & $10 / 49$ & 20.4 & $6 / 47$ & 12.8 \\
\hline Asymmetry (egocentric) (R, L) & $6 / 49$ & 12.2 & $5 / 47$ & 10.6 \\
\hline Left visual unilateral & $\mathrm{I} / 48$ & 2.1 & $\mathrm{I} / 48$ & 2.1 \\
\hline Right visual unilateral & $1 / 48$ & 2.1 & $0 / 48$ & 0 \\
\hline Left visual bilateral & $2 / 48$ & 4.2 & $3 / 48$ & 6.3 \\
\hline Right visual bilateral & $1 / 48$ & 2.1 & $4 / 48$ & 8.3 \\
\hline Left tactile unilateral & $5 / 48$ & 10.4 & $0 / 48$ & 0 \\
\hline Right tactile unilateral & $2 / 48$ & 4.2 & $0 / 48$ & 0 \\
\hline Left tactile bilateral & $4 / 48$ & 8.3 & $5 / 48$ & 10.4 \\
\hline Right tactile bilateral & $1 / 48$ & 2.1 & $7 / 48$ & 14.6 \\
\hline \multicolumn{5}{|l|}{ Controlled } \\
\hline Auditory attention accuracy & $6 / 48$ & 12.5 & $9 / 46$ & 19.6 \\
\hline Auditory attention practice & $11 / 48$ & 22.9 & $19 / 46$ & 41.3 \\
\hline Auditory attention word recall & $4 / 48$ & 8.3 & $8 / 46$ & 17.4 \\
\hline Sustained attention index & $5 / 45$ & II.I & $4 / 37$ & 10.8 \\
\hline Rule finding and set shifting accuracy & $9 / 48$ & 18.8 & $9 / 46$ & 19.6 \\
\hline \multicolumn{5}{|l|}{ Language } \\
\hline \multicolumn{5}{|l|}{ Spoken } \\
\hline Instruction comprehension & $20 / 47$ & 42.6 & $7 / 47$ & 14.9 \\
\hline Picture naming & $5 / 49$ & 10.2 & $2 / 48$ & 4.2 \\
\hline Sentence construction & $12 / 49$ & 24.5 & $10 / 48$ & 20.8 \\
\hline \multicolumn{5}{|l|}{ Written } \\
\hline Nonword reading-accuracy & $5 / 49$ & 10.2 & $9 / 48$ & 18.8 \\
\hline Sentence reading-accuracy & $10 / 49$ & 20.4 & $10 / 48$ & 20.8 \\
\hline Character writing & $7 / 41$ & 17.1 & $11 / 33$ & 33.3 \\
\hline \multicolumn{5}{|l|}{ Memory } \\
\hline \multicolumn{5}{|l|}{ Orientation } \\
\hline Personal & $5 / 50$ & 10 & $3 / 48$ & 6.3 \\
\hline Time and space & $11 / 50$ & 22 & $9 / 48$ & 18.8 \\
\hline \multicolumn{5}{|l|}{ Episodic } \\
\hline Story free-recall I & $19 / 50$ & 38 & $9 / 48$ & 18.8 \\
\hline Story recognition I & $15 / 50$ & 30 & $10 / 48$ & 20.8 \\
\hline Story free-recall 2 & $12 / 49$ & 24.5 & $11 / 47$ & 23.4 \\
\hline Story recognition 2 & $18 / 49$ & 36.7 & $6 / 47$ & 12.8 \\
\hline Task-recognition & $7 / 46$ & 15.2 & $5 / 47$ & 10.6 \\
\hline \multicolumn{5}{|l|}{ Number skills } \\
\hline \multicolumn{5}{|l|}{ Reading } \\
\hline Reading & $13 / 47$ & 27.7 & $12 / 47$ & 25.5 \\
\hline \multicolumn{5}{|l|}{ Writing } \\
\hline Writing & $7 / 46$ & 15.2 & $10 / 45$ & 22.2 \\
\hline \multicolumn{5}{|l|}{ Calculation } \\
\hline Calculation & $5 / 47$ & 10.6 & $7 / 46$ & 15.2 \\
\hline \multicolumn{5}{|l|}{ Praxis } \\
\hline Figure copy & $16 / 46$ & 34.8 & $18 / 45$ & 40 \\
\hline Multistep object use & $6 / 47$ & 12.8 & $13 / 47$ & 27.7 \\
\hline Gesture production & $10 / 47$ & 21.3 & $9 / 47$ & 19.1 \\
\hline Gesture recognition & $10 / 47$ & 21.3 & $13 / 47$ & 27.7 \\
\hline Imitation & $5 / 47$ & 10.6 & $7 / 47$ & 14.9 \\
\hline
\end{tabular}

Notes: Values are expressed as $\mathrm{n}(\%)$. Some of the scores were missing due to the fatigue and physical challenges.

Abbreviations: BCoS, Birmingham Cognitive Screen; R, right; L, left. 
Table 3 Correlations between the initial test scores and the retest scores

\begin{tabular}{|c|c|c|c|c|c|c|}
\hline & $\begin{array}{l}\text { Pearson } \\
\text { correlation } \\
\text { Controls + } \\
\text { Patients }\end{array}$ & $P$-value & $\begin{array}{l}\text { Pearson } \\
\text { correlation } \\
\text { Controls } \\
\text { alone }\end{array}$ & $P$-value & $\begin{array}{l}\text { Patients } \\
\text { alone }\end{array}$ & $P$-value \\
\hline \multicolumn{7}{|l|}{ Attention-spatial } \\
\hline Apple cancellation (overall score) & 0.551 & 0.004 & 0.799 & 0.003 & 0.276 & 0.320 \\
\hline \multicolumn{7}{|l|}{ Controlled } \\
\hline Auditory attention accuracy & 0.756 & $<0.001$ & 0.749 & 0.008 & $0.7 I I$ & 0.003 \\
\hline Rule finding and set shifting accuracy & 0.639 & $<0.001$ & 0.690 & 0.019 & 0.706 & 0.003 \\
\hline \multicolumn{7}{|l|}{ Language-spoken } \\
\hline Picture naming & 0.399 & 0.044 & 0.593 & 0.055 & 0.341 & 0.214 \\
\hline Sentence construction & 0.077 & 0.709 & 0.671 & 0.024 & NA & NA \\
\hline \multicolumn{7}{|l|}{ Written } \\
\hline Sentence reading-accuracy & 0.843 & $<0.001$ & 0.464 & 0.150 & 0.907 & $<0.001$ \\
\hline Nonword reading accuracy & 0.483 & 0.013 & 0.467 & 0.148 & 0.535 & 0.040 \\
\hline \multicolumn{7}{|l|}{ Memory-episodic } \\
\hline Story free-recall I & 0.485 & 0.012 & 0.483 & 0.133 & 0.416 & 0.123 \\
\hline Story recognition I & 0.645 & $<0.001$ & 0.596 & 0.053 & 0.655 & 0.008 \\
\hline Story free-recall 2 & 0.598 & 0.001 & 0.720 & 0.013 & 0.500 & 0.058 \\
\hline Story recognition 2 & 0.320 & 0.111 & 0.313 & 0.349 & 0.406 & 0.133 \\
\hline \multicolumn{7}{|l|}{ Number skills } \\
\hline Number reading & 0.793 & $<0.001$ & 0.391 & 0.234 & 0.947 & $<0.001$ \\
\hline Number writing & 0.615 & 0.001 & 0.671 & 0.024 & NA & NA \\
\hline Calculation & 0.603 & 0.001 & 0.608 & 0.047 & 0.639 & 0.010 \\
\hline \multicolumn{7}{|l|}{ Praxis } \\
\hline Complex figure copy & 0.559 & 0.001 & 0.516 & 0.104 & 0.491 & 0.063 \\
\hline Gesture production & 0.652 & $<0.001$ & 0.443 & 0.172 & 0.723 & 0.002 \\
\hline Imitation & 0.528 & 0.006 & 0.934 & 0.000 & 0.374 & 0.170 \\
\hline
\end{tabular}

Notes: NA signifies tests where correlations could not be performed due to lack of variance in the data.

The results indicate reliable correlations between the subtests of the $\mathrm{BCoS}$ and the standard tests chosen to measure selective cognitive functions.

\section{Performance of patients with aphasia}

Due to its design (ie, the use of short, high-frequency words and forced-choice testing), the $\mathrm{BCoS}$ is able to gain measures on many functions for patients with language problems. This is less apparent for other screens, such as the MMSE and the MoCA, where measures depend on the patients having good spoken language. To assess the effectiveness of the $\mathrm{BCoS}$ for these patients, we examined the performance of patients with and without a problem on the sentence construction test of the tests of controlled attention (auditory attention and executive function), memory (story free- recall 1 and story recognition 1), character writing, and praxis (figure copy and multistep object use). Patients were defined as having a spoken language problem if they fell beneath the cutoff on the sentence construction test. We divided patients into two subgroups based on their sentence construction scores. Table 5 presents the numbers of patients in each group who were impaired on the tests mentioned above, according to the cutoffs given in Table 1 . The comparisons of incidence rate of disability in controlled attention, memory, character writing, and praxis, between patients with and without spoken problem were presented in Table 5 as well.

The table indicates that the aphasic patients largely performed worse than the nonaphasic patients in most of the subtests. Nevertheless, in very many cases, at least half the aphasic patients were able to generate normal scores on other aspects of the $\mathrm{BCoS}$.

\section{Discussion}

There is currently no screen for Chinese individuals (Cantonese speakers) that has been specially designed (ie, being "aphasia and neglect friendly") to maximize the inclusion of patients after stroke while being sensitive to common cognitive problems after stroke (such as spatial neglect and apraxia). To rectify this, we constructed a Cantonese version 
Table 4 Correlations with comparable standardized tasks

\begin{tabular}{|c|c|c|c|c|c|}
\hline Domain & Task name & Validation task & $\mathbf{N}$ & $R$ & P-value \\
\hline \multirow[t]{4}{*}{ Attention-spatial } & Apple cancellation accuracy & Total number of lines crossed on & 70 & 0.630 & 0.000 \\
\hline & & Albert's test & & & \\
\hline & Asymmetry (allocentric) (R, L) & Albert cancellation test-asymmetry & 70 & 0.304 & 0.010 \\
\hline & Asymmetry (egocentric) (R, L) & Albert cancellation test-asymmetry & 70 & 0.429 & 0.000 \\
\hline \multirow[t]{5}{*}{ Attention-controlled } & Auditory attention accuracy & MoCA-attention (read and subjects tap) & 191 & 0.385 & 0.000 \\
\hline & & MoCA attention (total score) & 191 & 0.518 & 0.000 \\
\hline & & MoCA attention (digit span) & 191 & 0.224 & 0.002 \\
\hline & Rule finding and set shifting accuracy & MoCA-attention (total score) & 191 & 0.406 & 0.000 \\
\hline & Rule finding and set shifting accuracy & MoCA visuospatial/executive & 191 & 0.508 & 0.000 \\
\hline \multirow[t]{3}{*}{ Language-spoken } & Instruction comprehension & MoCA-language (total score) & 192 & 0.436 & 0.000 \\
\hline & Picture naming & MoCA-naming & 191 & 0.254 & 0.000 \\
\hline & Sentence construction & MoCA-language (total score) & 192 & 0.416 & 0.000 \\
\hline \multirow[t]{5}{*}{ Language reading } & Nonwords reading & MoCA-language (total score) & 191 & 0.322 & 0.000 \\
\hline & & MMSE-reading & 102 & 0.388 & 0.000 \\
\hline & Sentence reading & MoCA-language (total score) & 191 & 0.331 & 0.000 \\
\hline & & MMSE-reading & 102 & 0.365 & 0.000 \\
\hline & Character writing & MMSE-writing & 102 & 0.444 & 0.000 \\
\hline \multirow[t]{4}{*}{ Memory-orientation } & Time and space & MoCA-orientation & 190 & 0.568 & 0.000 \\
\hline & & MMSE-orientation & 102 & 0.452 & 0.000 \\
\hline & Time and space (MCQ) & MoCA-orientation & 190 & 0.730 & 0.000 \\
\hline & & MMSE-orientation & 102 & 0.665 & 0.000 \\
\hline \multirow[t]{11}{*}{ Memory episodic } & Story free-recall I & MoCA-delayed recall and & 191 & 0.397 & 0.000 \\
\hline & (immediate recall) & MMSE delayed recall & & & \\
\hline & & MMSE-delay recall & 103 & 0.390 & 0.000 \\
\hline & Story recognition & MoCA-delay recall & 191 & 0.335 & 0.000 \\
\hline & (immediate recognition) & MMSE-delay recall & 103 & 0.314 & 0.001 \\
\hline & Story free-recall 2 & MoCA-delay recall & 191 & 0.495 & 0.000 \\
\hline & (delayed free-recall) & MMSE-delay recall & 103 & 0.556 & 0.000 \\
\hline & Story recognition 2 & MoCA-delay recall & 191 & 0.346 & 0.000 \\
\hline & & MMSE-delay recall & 103 & 0.385 & 0.000 \\
\hline & Task-recognition & MoCA-delay recall & 191 & 0.327 & 0.000 \\
\hline & & MMSE-delay recall & 103 & 0.219 & 0.026 \\
\hline \multirow[t]{4}{*}{ Number skills } & Reading & MoCA-calculation (serial 7) & 191 & 0.482 & 0.000 \\
\hline & Writing & MoCA-calculation (serial 7) & 191 & 0.303 & 0.000 \\
\hline & Calculation & MoCA-calculation (serial 7) & 191 & 0.454 & 0.000 \\
\hline & & MMSE-calculation & 103 & 0.555 & 0.000 \\
\hline \multirow[t]{5}{*}{ Praxis } & Complex figure copy & Rey-Osterrieth Complex Figure Test & 64 & 0.650 & 0.000 \\
\hline & Multistep object use & Gestural imitation score (Goldenberg) ${ }^{23}$ & 71 & 0.474 & 0.000 \\
\hline & Gesture production & Gestural imitation score (Goldenberg) ${ }^{23}$ & 71 & 0.583 & 0.000 \\
\hline & Gesture recognition & Gestural imitation score (Goldenberg) ${ }^{23}$ & 71 & 0.479 & 0.000 \\
\hline & Imitation & Gestural imitation score (Goldenberg) ${ }^{23}$ & 71 & 0.626 & 0.000 \\
\hline
\end{tabular}

Abbreviations: MCQ, multi choice question; MMSE, Mini Mental State Examination; MoCA, Montreal Cognitive Assessment test; R, right; L, left.

Table 5 Numbers of patients in each group who were impaired on the tests

\begin{tabular}{|c|c|c|c|c|c|c|}
\hline & \multicolumn{2}{|c|}{$\begin{array}{l}\text { Patients with } \\
\text { problem in sentence } \\
\text { construction }\end{array}$} & \multicolumn{2}{|c|}{$\begin{array}{l}\text { Patients without } \\
\text { problem in sentence } \\
\text { construction }\end{array}$} & \multirow[t]{2}{*}{$\chi^{2}$} & \multirow[t]{2}{*}{$P$-value } \\
\hline & $\mathbf{N}$ & $\%$ & $\mathbf{N}$ & $\%$ & & \\
\hline Auditory attention & $8 / 20$ & 40 & $7 / 74$ & 9.5 & 10.950 & 0.001 \\
\hline Rule finding and set shifting accuracy & $11 / 20$ & 55 & $7 / 74$ & 9.5 & 21.091 & 0.000 \\
\hline character writing & $8 / 15$ & 53.3 & $10 / 59$ & 16.9 & 8.601 & 0.003 \\
\hline Story free-recall I & $9 / 22$ & 40.9 & $18 / 75$ & 24 & 2.421 & 0.120 \\
\hline Story recognition I & $13 / 22$ & 59.1 & $12 / 75$ & 16 & 16.510 & 0.000 \\
\hline Figure copy & $15 / 19$ & 78.9 & $19 / 72$ & 26.4 & 15.570 & 0.000 \\
\hline Multistep object use & $8 / 20$ & 40 & II/74 & 14.9 & 6.618 & 0.013 \\
\hline
\end{tabular}


of the $\mathrm{BCoS}$, a screen designed specifically to address these problems in English. We showed that the Cantonese version $\mathrm{BCoS}$ has high convergent validity; there were reliable correlations between each of the subtests and standard tests in the literature chosen to assess a particular aspect of cognition. This demonstrates that the Cantonese version $\mathrm{BCoS}$ does indeed assess the subfunctions being proposed. The Cantonese version $\mathrm{BCoS}$ also had good test-retest reliability, and there was good reliability across trained testers in the scoring of the qualitative aspects of the screen. Moreover, by using the screen, we were able to generate scores on nonlanguage-based tests in patients with poor language (eg, the measures of executive function in patients with poor picture naming). Thus the Cantonese version $\mathrm{BCoS}$ can be very useful for generating cognitive profiles that are (relatively) uncontaminated by poor language, in stroke patients.

The screen did indicate that there were relatively high numbers of patients with cognitive impairments after their stroke. Around $40 \%$ of the patients showed poor figure copy, and $30 \%$ were impaired on the $\mathrm{BCoS}$ measures of sustained attention - these tests either use nonverbal or (at most) very simple linguistic material, so it is interesting that high incidence rates were noted. In addition to this, there were high incidence rates for apraxia and impaired spatial attention ( $~ 27 \%$ of the sample were impaired on the multistep object use task and on gesture recognition, and $28 \%$ of patients had an impairment on the test of spatial attention). Given that these impairments are not measured in standard screens currently applied in the People's Republic of China (ie, the MoCA and the MMSE), the Cantonese version BCoS certainly has distinct advantages. Notably, the majority of subjects recruited in our patient group had lacunar infarction (57 out of 98 patients in our group suffered from small-artery occlusion). According to previous studies, mild cognitive impairment was present in up to $50 \%$ of patients with lacunar stroke, even in those with minimal or without physical disabilities..$^{25,26}$ Other research has shown that more than half of patients with a first-ever lacunar stroke and without cognitive impairment show minor neuropsychological alterations, particularly in the performance of executive functions (eg, semantic fluency) and short-delayed verbal memory. Therefore it is very important to include a "neuropsychological study" in future clinical trials in patients with lacunar stroke. ${ }^{27}$

Another advantage of the Cantonese version $\mathrm{BCoS}$ compared with other current screens relates to the procedures for reporting $\mathrm{BCoS}$ scores. The $\mathrm{BCoS}$ uses a "wheel of cognition", which enables deficits (or strengths) in particular domains of cognition to be grasped at a glance (Figure S1).
This facilitates the reporting of domain-specific deficits (rather than reporting back a single score, as is done for the MoCA and the MMSE), which we suggest is important in order to target rehabilitation at the subdomains that are affected in the patients. We suggest that the combined use of the Cantonese version $\mathrm{BCoS}$ and of its reporting scheme will substantially improve the early detection and rehabilitation of cognitive problems after stroke in the People's Republic of China.

However, there were still some limitation in our study. Firstly, the stroke patients recruited in the study generally had relatively low NIHSS scores, indicating that their neurological functions were mildly to moderately impaired. Hence it is unclear whether the Cantonese version BCoS is effective enough for stroke patients with severe neurological impairments. Secondly, our sample size was relatively small. Therefore a larger sample for reassessment is needed in the future study, to make the data more representative. Finally, since the time required for completing the questionnaire is about 1 hour, some patient data were missing because of fatigue or inability to concentrate for such a lengthy period.

\section{Acknowledgments}

This work was supported by a grant from the Science and Technology Program of Guangzhou, People's Republic of China (grant number 2012J5100039).

\section{Disclosure}

The authors report no conflicts of interest in this work.

\section{References}

1. Tsai CF, Thomas B, Sudlow CL. Epidemiology of stroke and its subtypes in Chinese vs white populations: a systematic review. Neurology. 2013;81(3):264-272.

2. Rasquin SM, Lodder J, Visser PJ, Lousberg R, Verhey FR. Predictive accuracy of MCI subtypes for Alzheimer's disease and vascular dementia in subjects with mild cognitive impairment: a 2-year follow-up study. Dement Geriatr Cogn Disord. 2005;19(2-3):113-119.

3. Alvarez-Sabín J, Román GC. Citicoline in vascular cognitive impairment and vascular dementia after stroke. Stroke. 2011;42(1 Suppl) S40-S43.

4. Blackburn DJ, Krishnan K, Fox L, et al. Prevention of Decline in Cognition after Stroke Trial (PODCAST): a study protocol for a factorial randomised controlled trial of intensive versus guideline lowering of blood pressure and lipids. Trials. 2013;14:401.

5. Erkinjuntti T, Román G, Gauthier S, Feldman H, Rockwood K. Emerging therapies for vascular dementia and vascular cognitive impairment. Stroke. 2004;35(4):1010-1017.

6. Folstein MF, Folstein SE, McHugh PR. "Mini-mental state". A practical method for grading the cognitive state of patients for the clinician. J Psychiatr Res. 1975;12(3):189-198.

7. Nasreddine ZS, Phillips NA, Bédirian V, et al. The Montreal Cognitive Assessment, MoCA: A brief screening tool for mild cognitive impairment. J Am Geriatr Soc. 2005;53(4):695-699. 
8. Dong Y, Sharma VK, Chan BP, et al. The Montreal Cognitive Assessment (MoCA) is superior to the Mini-Mental State Examination (MMSE) for the detection of vascular cognitive impairment after acute stroke. J Neurol Sci. 2010;299(1-2):15-18.

9. Pendlebury ST, Cuthbertson FC, Welch SJ, Mehta Z, Rothwell PM. Underestimation of cognitive impairment by Mini-Mental State Examination versus the Montreal Cognitive Assessment in patients with transient ischemic attack and stroke: a population-based study. Stroke. 2010;41(6):1290-1293.

10. Bickerton WL, Riddoch MJ, Samson D, Balani AB, Mistry B, Humphreys GW. Systematic assessment of apraxia and functional predictions from the Birmingham Cognitive Screen. J Neurol Neurosurg Psychiatry. 2012;83(5):513-521.

11. Bickerton WL, Samson D, Williamson J, Humphreys GW. Separating forms of neglect using the Apples Test: validation and functional prediction in chronic and acute stroke. Neuropsychology. 2011;25(5): 567-580.

12. Chechlacz M, Rotshtein P, Roberts KL, Bickerton WL, Lau JK, Humphreys GW. The prognosis of allocentric and egocentric neglect: evidence from clinical scans. PLoS One. 2012;7(11):e47821.

13. Nys GM, van Zandvoort MJ, de Kort PL, et al. The prognostic value of domain-specific cognitive abilities in acute first-ever stroke. Neurology. 2005;64(5):821-827.

14. Bisiker J, Bickerton W-L. Using a comprehensive and standardised cognitive screen to guide cognitive rehabilitation in stroke. Br J Occup Ther. 2013;76(3):151-156.

15. Wong A, Xiong YY, Kwan PW, et al. The validity, reliability and clinical utility of the Hong Kong Montreal Cognitive Assessment (HK-MoCA) in patients with cerebral small vessel disease. Dement Geriatr Cogn Disord. 2009;28(1):81-87.

16. Yeung PY, Wong LL, Chan CC, Leung JL, Yung CY. A validation study of the Hong Kong version of Montreal Cognitive Assessment (HK-MoCA) in Chinese older adults in Hong Kong. Hong Kong Med J. 2014;20(6):504-510.
17. Humphreys GW, Bickerton W-L, Sampson D, Riddoch M. BCoS cognitive screen. Hove: Psychology Press; 2012.

18. Lee CY, Tsai JL, Su EC, Tzeng OJ, Hung DL. Consistency, regularity, and frequency effects in naming Chinese charcters. Lang Linguist. 2005;6(1):75-107.

19. Venezky RL. The Structure of English Orthography. The Hague, the Netherlands: Mouton; 1970.

20. Bauer RS, Benedict PK. Modern Cantonese phonology. Berlin: Mouton de Gruyter; 1997.

21. Albert ML. A simple test of visual neglect. Neurology. 1973;23(6): 658-664.

22. Cherrier, MM, Mendez MF, Dave M, Perryman KM. Performance on the Rey-Osterrieth Complex Figure Test in Alzheimer disease and vascular dementia. Cognitive and Behavioral Neurology. Neuropsychiatry Neuropsychol Behav Neurol. 1999;12(2):95-101.

23. Goldenberg G. Defective imitation of gestures in patients with damage in the left or right hemispheres. J Neurol Neurosurg Psychiatry. 1996;61(2):176-180.

24. Adams HP, Bendixen BH, Kappelle LJ, et al. Classification of subtype of acute ischemic stroke. Definitions for use in a multicenter clinical trial. TOAST. Trial of Org 10172 in Acute Stroke Treatment. Stroke. 1993;24(1):35-41.

25. Jacova C, Pearce LA, Costello R, et al. Cognitive impairment in lacunar strokes: the SPS3 trial. Ann Neurol. 2012;72(3):351-362.

26. Grau-Olivares M, Arboix A, Bartrés-Faz D, Junqué C. Neuropsychological abnormalities associated with lacunar infarction. J Neurol Sci. 2007;257(1-2):160-165.

27. Blanco-Rojas L, Arboix A, Canovas D, Grau-Olivares M, Oliva Morera JC, Parra O. Cognitive profile in patients with a first-ever lacunar infarct with and without silent lacunes: a comparative study. BMC Neurol. $2013 ; 13: 203$ 


\section{Supplementary materials \\ Birmingham Cognitive Screen (BCoS)-Cantonese}

Table SI The comparison in age and education years between controls and patients within each age group (mean \pm standard deviation)

\begin{tabular}{|c|c|c|c|c|c|c|}
\hline & \multicolumn{3}{|l|}{ 50-69 years } & \multicolumn{3}{|l|}{$\geq 70$ years } \\
\hline & Patient group & Control group & $P$-value & Patient group & Control group & $P$-value \\
\hline Age (years) & $60.78 \pm 5.80$ & $60.86 \pm 4.98$ & 0.93 & $76.35 \pm 4.43$ & $77.36 \pm 4.80$ & 0.31 \\
\hline Years of education & $8.47 \pm 2.95$ & $9.18 \pm 3.62$ & 0.24 & $6.89 \pm 4.64$ & $8.97 \pm 5.39$ & 0.06 \\
\hline
\end{tabular}

Table S2 Comparisons of test-retest scores (pooled across patients and controls)

\begin{tabular}{|c|c|c|c|c|c|c|c|}
\hline \multirow[t]{2}{*}{ Tasks-patient and control group } & \multirow[t]{2}{*}{ Range } & \multicolumn{2}{|c|}{ Ist test } & \multicolumn{2}{|c|}{ 2nd test } & \multirow{2}{*}{$\begin{array}{l}\text { Wilcoxon } \\
\text { signed rank } \\
P \text {-value }\end{array}$} & \multirow{2}{*}{$\begin{array}{l}\text { \% exact score } \\
\text { agreement }\end{array}$} \\
\hline & & Mean & SD & Mean & SD & & \\
\hline \multicolumn{8}{|l|}{ Attention-spatial } \\
\hline Apple cancellation (overall score) & $0-50$ & 47.04 & 3.04 & 48.08 & 1.65 & 0.063 & 34.6 \\
\hline \multicolumn{8}{|l|}{ Controlled } \\
\hline Auditory attention accuracy & $0-54$ & 50.38 & 5.29 & 50.73 & 4.30 & 0.269 & 30.8 \\
\hline Rule finding accuracy & $0-18$ & 12.85 & 2.96 & 13.23 & 3.13 & 0.313 & 30.8 \\
\hline \multicolumn{8}{|l|}{ Language-spoken } \\
\hline Picture naming & $1-14$ & 13.35 & 0.80 & 13.38 & 0.70 & 0.776 & 57.7 \\
\hline Sentence construction & $0-8$ & 7.69 & 0.74 & 7.92 & 0.27 & $0.13 \mid$ & 80.8 \\
\hline \multicolumn{8}{|l|}{ Written } \\
\hline Sentence reading-accuracy & $0-40$ & 39.00 & 1.88 & 38.96 & 2.05 & 0.763 & 65.4 \\
\hline Nonword reading accuracy & $0-6$ & 5.77 & 0.59 & 5.81 & 0.40 & 0.705 & 73.1 \\
\hline \multicolumn{8}{|l|}{ Memory-episodic } \\
\hline Story free-recall I & $0-15$ & 6.21 & 2.20 & 7.44 & 2.04 & 0.014 & 15.4 \\
\hline Story recognition I & $0-15$ & 11.92 & 1.83 & 12.92 & 1.38 & 0.003 & 15.4 \\
\hline Story free-recall 2 & $0-15$ & 8.35 & 2.51 & 9.88 & 2.37 & 0.004 & 7.7 \\
\hline Story recognition 2 & $0-15$ & 13.73 & 1.12 & 14.38 & 0.64 & 0.007 & 30.8 \\
\hline \multicolumn{8}{|l|}{ Number skills } \\
\hline Number reading & $0-9$ & 8.73 & 0.67 & 8.77 & 0.71 & 0.655 & 80.8 \\
\hline Number writing & $0-5$ & 4.77 & 0.59 & 4.88 & 0.59 & 0.257 & 84.6 \\
\hline Calculation & $0-4$ & 3.69 & 0.62 & 3.65 & 0.56 & 0.705 & 73.1 \\
\hline \multicolumn{8}{|l|}{ Praxis } \\
\hline Complex figure copy & $0-47$ & 42.92 & 2.61 & 43.85 & 3.02 & 0.034 & 15.4 \\
\hline Gesture production & $0-12$ & 11.04 & 1.28 & 11.35 & 0.85 & 0.082 & 57.7 \\
\hline Gesture recognition & $0-6$ & 5.88 & 0.33 & 6.00 & 0.00 & 0.083 & 88.5 \\
\hline Imitation & $0-12$ & 11.12 & 1.18 & 11.12 & 1.18 & 0.683 & 57.7 \\
\hline
\end{tabular}

Abbreviation: SD, standard deviation. 
Table S3 Comparisons of test-retest scores (control group)

\begin{tabular}{|c|c|c|c|c|c|c|c|}
\hline \multirow[t]{2}{*}{ Tasks (control group) } & \multirow[t]{2}{*}{ Range } & \multicolumn{2}{|c|}{ Ist test } & \multicolumn{2}{|c|}{ 2nd test } & \multirow{2}{*}{$\begin{array}{l}\text { Wilcoxon } \\
\text { signed rank } \\
P \text {-value }\end{array}$} & \multirow{2}{*}{$\begin{array}{l}\text { \% exact score } \\
\text { agreement }\end{array}$} \\
\hline & & Mean & SD & Mean & SD & & \\
\hline \multicolumn{8}{|l|}{ Attention-spatial } \\
\hline Apple cancellation overall score & $0-50$ & 45.64 & 4.06 & 48.00 & 1.79 & 0.027 & 45.5 \\
\hline \multicolumn{8}{|l|}{ Controlled } \\
\hline Auditory attention accuracy & $0-54$ & 52.55 & 2.34 & 52.82 & 1.89 & 0.454 & 18.2 \\
\hline Rule finding accuracy & $0-18$ & 12.18 & 2.86 & 13.64 & 1.96 & 0.039 & 36.4 \\
\hline \multicolumn{8}{|l|}{ Language-spoken } \\
\hline Picture naming & $1-14$ & 13.45 & 0.69 & 13.18 & 0.60 & 0.317 & 63.6 \\
\hline Sentence construction & $0-8$ & 7.91 & 0.30 & 7.91 & 0.30 & 0.317 & 90.1 \\
\hline \multicolumn{8}{|l|}{ Written } \\
\hline Sentence reading-accuracy & $0-40$ & 39.18 & 1.17 & 39.27 & 1.19 & 0.854 & 63.6 \\
\hline Nonword reading accuracy & $0-6$ & 5.64 & 0.67 & 5.82 & 0.41 & 0.317 & 63.6 \\
\hline \multicolumn{8}{|l|}{ Memory-episodic } \\
\hline Story free-recall I & $0-15$ & 6.73 & 2.79 & 8.23 & 2.21 & 0.102 & 9.1 \\
\hline Story recognition I & $0-15$ & 12.36 & 1.91 & 13.45 & $\mid .5 \mathrm{I}$ & 0.046 & 18.2 \\
\hline Story free-recall 2 & $0-15$ & 8.86 & 3.16 & 10.73 & 2.10 & 0.029 & 0 \\
\hline Story recognition 2 & $0-15$ & 14.27 & 0.91 & 14.36 & 0.65 & 0.739 & 54.5 \\
\hline \multicolumn{8}{|l|}{ Number skills } \\
\hline Number reading & $0-9$ & 8.73 & 0.47 & 8.73 & 0.65 & 1.000 & 63.6 \\
\hline Number writing & $0-5$ & 4.64 & 0.81 & 4.73 & 0.91 & 0.655 & 81.8 \\
\hline Calculation & $0-4$ & 3.64 & 0.67 & 3.45 & 0.69 & 0.317 & 63.6 \\
\hline \multicolumn{8}{|l|}{ Praxis } \\
\hline Complex figure copy & $0-47$ & 44.27 & 1.90 & 45.45 & 1.70 & 0.058 & 18.2 \\
\hline Gesture production & $0-12$ & 11.27 & 1.10 & 11.55 & 0.69 & 0.334 & 54.5 \\
\hline Gesture recognition & $0-6$ & 5.91 & 0.30 & 6.00 & 0.00 & 0.317 & 90.9 \\
\hline Imitation & $0-12$ & 11.18 & 1.17 & 11.55 & 0.69 & 1.000 & 81.8 \\
\hline
\end{tabular}

Abbreviation: SD, standard deviation.

Table S4 Comparisons of test-retest scores (patient group)

\begin{tabular}{|c|c|c|c|c|c|c|c|}
\hline \multirow[t]{2}{*}{ Tasks (patient group) } & \multirow[t]{2}{*}{ Range } & \multicolumn{2}{|c|}{ Ist test } & \multicolumn{2}{|c|}{ 2nd test } & \multirow{2}{*}{$\begin{array}{l}\text { Wilcoxon } \\
\text { signed rank } \\
P \text {-value }\end{array}$} & \multirow{2}{*}{$\begin{array}{l}\text { \% exact score } \\
\text { agreement }\end{array}$} \\
\hline & & Mean & SD & Mean & SD & & \\
\hline \multicolumn{8}{|l|}{ Attention-spatial } \\
\hline Apple cancellation & $0-50$ & 48.07 & 1.44 & 48.13 & 1.60 & 0.893 & 26.7 \\
\hline \multicolumn{8}{|l|}{ Controlled } \\
\hline Auditory attention accuracy & $0-54$ & 48.80 & 6.29 & 49.20 & 4.95 & 0.511 & 40 \\
\hline Rule finding accuracy & $0-18$ & 13.33 & 3.04 & 12.93 & 3.81 & 0.823 & 26.7 \\
\hline \multicolumn{8}{|l|}{ Language-spoken } \\
\hline Picture naming & $1-14$ & 13.27 & 0.88 & 13.47 & 0.74 & 0.380 & 53.3 \\
\hline Sentence construction & $0-8$ & 7.53 & 0.92 & 8.00 & 0.00 & 0.066 & 73.3 \\
\hline \multicolumn{8}{|l|}{ Written } \\
\hline Sentence reading-accuracy & $0-40$ & 38.87 & 2.30 & 38.73 & 2.520 & 0.492 & 66.7 \\
\hline Nonword reading accuracy & $0-6$ & 5.87 & 0.52 & 5.80 & $0.4 I$ & 0.564 & 80 \\
\hline \multicolumn{8}{|l|}{ Memory-episodic } \\
\hline Story free-recall I & $0-15$ & 5.83 & 1.64 & 6.87 & 1.77 & 0.059 & 20 \\
\hline Story recognition I & $0-15$ & 11.60 & 1.77 & 12.53 & 1.19 & 0.026 & 13.3 \\
\hline Story free-recall 2 & $0-15$ & 7.967 & 1.93 & 9.27 & 2.43 & 0.064 & 13.3 \\
\hline Story recognition 2 & $0-15$ & 13.33 & I.II & 14.40 & 0.63 & 0.005 & 20 \\
\hline \multicolumn{8}{|l|}{ Number skills } \\
\hline Number reading & $0-9$ & 8.73 & 0.80 & 8.80 & 0.78 & 0.317 & 93.3 \\
\hline Number writing & $0-5$ & 4.87 & 0.35 & 5.00 & 0.00 & 0.157 & 86.7 \\
\hline Calculation & $0-4$ & 3.73 & 0.59 & 3.80 & 0.41 & 0.564 & 80 \\
\hline \multicolumn{8}{|l|}{ Praxis } \\
\hline Complex figure copy & $0-47$ & 41.93 & 2.66 & 42.67 & 3.27 & 0.216 & 13.3 \\
\hline Gesture production & $0-12$ & 10.87 & 1.41 & 11.20 & 0.94 & 0.163 & 60 \\
\hline Gesture recognition & $0-6$ & 5.87 & 0.35 & 6.00 & 0.00 & 0.157 & 86.7 \\
\hline Imitation & $0-12$ & 10.87 & 1.99 & 11.07 & 1.16 & 0.675 & 40 \\
\hline
\end{tabular}

Abbreviation: SD, standard deviation. 
Table S5 Interrater reliability for the sentence construction tasks, multistep object use, gesture production, gesture imitation, and figure copying

\begin{tabular}{llll}
\hline Task & ICC (interclass correlations) & $\mathbf{9 5 \%} \mathbf{C l}$ & \% exact score agreement \\
\hline Sentence construction & 0.92 & $0.80-0.98$ & \\
Multistep object use & - & - & $100 \%$ \\
Gesture production & - & - & $100 \%$ \\
Imitation & 0.987 & $0.96-0.99$ & \\
Figure copy & 0.993 & $0.98-0.99$ & \\
\hline
\end{tabular}

Abbreviations: $\mathrm{Cl}$, confidence interval; ICC, the mean correlation coefficient across the three raters.

Table S6 Subtests of BCoS compared with the validation task in the patient group

\begin{tabular}{|c|c|c|c|c|c|}
\hline Domain & Task name & Validation task & $\mathbf{N}$ & Correl $(R)$ & $P$-value \\
\hline \multirow[t]{3}{*}{ Attention-spatial } & Apple cancellation accuracy & Total number of crossed lines (Albert's test) & 56 & 0.631 & 0.000 \\
\hline & Asymmetry (allocentric) (R, L) & Albert cancellation test-asymmetry & 56 & 0.311 & 0.019 \\
\hline & Asymmetry (egocentric) (R, L) & Albert cancellation test-asymmetry & 56 & 0.486 & 0.000 \\
\hline \multirow[t]{4}{*}{ Attention-controlled } & Auditory attention accuracy & MoCA-attention (read and subjects tap) & 74 & 0.385 & 0.001 \\
\hline & & MoCA attention (total score) & 74 & 0.592 & 0.000 \\
\hline & & MoCA attention (digit span) & 74 & 0.331 & 0.004 \\
\hline & Rule finding accuracy & MoCA-attention (total score) & 74 & 0.500 & 0.000 \\
\hline \multirow[t]{3}{*}{ Language-spoken } & Instruction comprehension & MoCA-language (total score) & 74 & 0.524 & 0.000 \\
\hline & Picture naming & MoCA-naming & 74 & 0.230 & 0.049 \\
\hline & Sentence construction & MoCA-language (total score) & 74 & 0.488 & 0.000 \\
\hline \multirow[t]{5}{*}{ Language reading } & Nonwords reading & MoCA-language (total score) & 74 & 0.336 & 0.000 \\
\hline & & MMSE-reading & 65 & 0.440 & 0.000 \\
\hline & Sentence reading & MoCA-language (total score) & 74 & 0.361 & 0.002 \\
\hline & & MMSE-reading & 65 & 0.406 & 0.001 \\
\hline & Character writing & MMSE-writing & 65 & 0.549 & 0.000 \\
\hline \multirow[t]{4}{*}{ Memory-orientation } & Time and space & MoCA-orientation & 73 & 0.584 & 0.000 \\
\hline & & MMSE-orientation & 64 & 0.424 & 0.000 \\
\hline & Time and space (MCQ) & MoCA-orientation & 73 & 0.790 & 0.000 \\
\hline & & MMSE-orientation & 64 & 0.675 & 0.000 \\
\hline \multirow[t]{11}{*}{ Memory episodic } & Story free-recallI & MoCA-delay recall & 74 & 0.337 & 0.003 \\
\hline & (Immediate recall) & MMSE-delay recall & 65 & 0.458 & 0.000 \\
\hline & Story recognition & MoCA-delay recal & 74 & 0.370 & 0.001 \\
\hline & (immediate recognition) & MMSE-delay recall and & 65 & 0.307 & 0.013 \\
\hline & & MoCA-delayed recall & & & \\
\hline & Story free-recall 2 & MoCA-delay recall & 74 & 0.428 & 0.000 \\
\hline & (delayed free recall) & MMSE-delay recall & 65 & 0.524 & 0.000 \\
\hline & Story recognition 2 & MoCA-delay recall & 74 & 0.319 & 0.006 \\
\hline & & MMSE-delay recall & 65 & 0.352 & 0.004 \\
\hline & Task recognition & MoCA-delay recall & 74 & 0.315 & 0.006 \\
\hline & & MMSE-delay recall & 74 & 0.084 & 0.506 \\
\hline \multirow[t]{4}{*}{ Number skills } & Reading & MoCA-calculation (serial 7) & 74 & 0.600 & 0.000 \\
\hline & Writing & MoCA-calculation (serial 7) & 74 & 0.336 & 0.003 \\
\hline & Calculation & MoCA-calculation (serial 7) & 74 & 0.570 & 0.000 \\
\hline & & MMSE-calculation & 74 & 0.615 & 0.000 \\
\hline \multirow[t]{5}{*}{ Praxis } & Complex figure copy & Rey-Osterrieth Complex Figure Test & 49 & 0.621 & 0.000 \\
\hline & Multistep object use & - & 56 & & \\
\hline & Gesture production & Gestural imitation score (Goldenberg) & 57 & 0.552 & 0.000 \\
\hline & Gesture recognition & Gestural imitation score (Goldenberg) & 57 & 0.451 & 0.000 \\
\hline & Imitation & Gestural imitation score (Goldenberg) & 57 & 0.610 & 0.000 \\
\hline
\end{tabular}

Abbreviations: BCoS, Birmingham Cognitive Screen; MCQ, multi choice questions; MMSE, Mini Mental State Examination; MoCA, Montreal Cognitive Assessment test; $L$, left; R, right. 


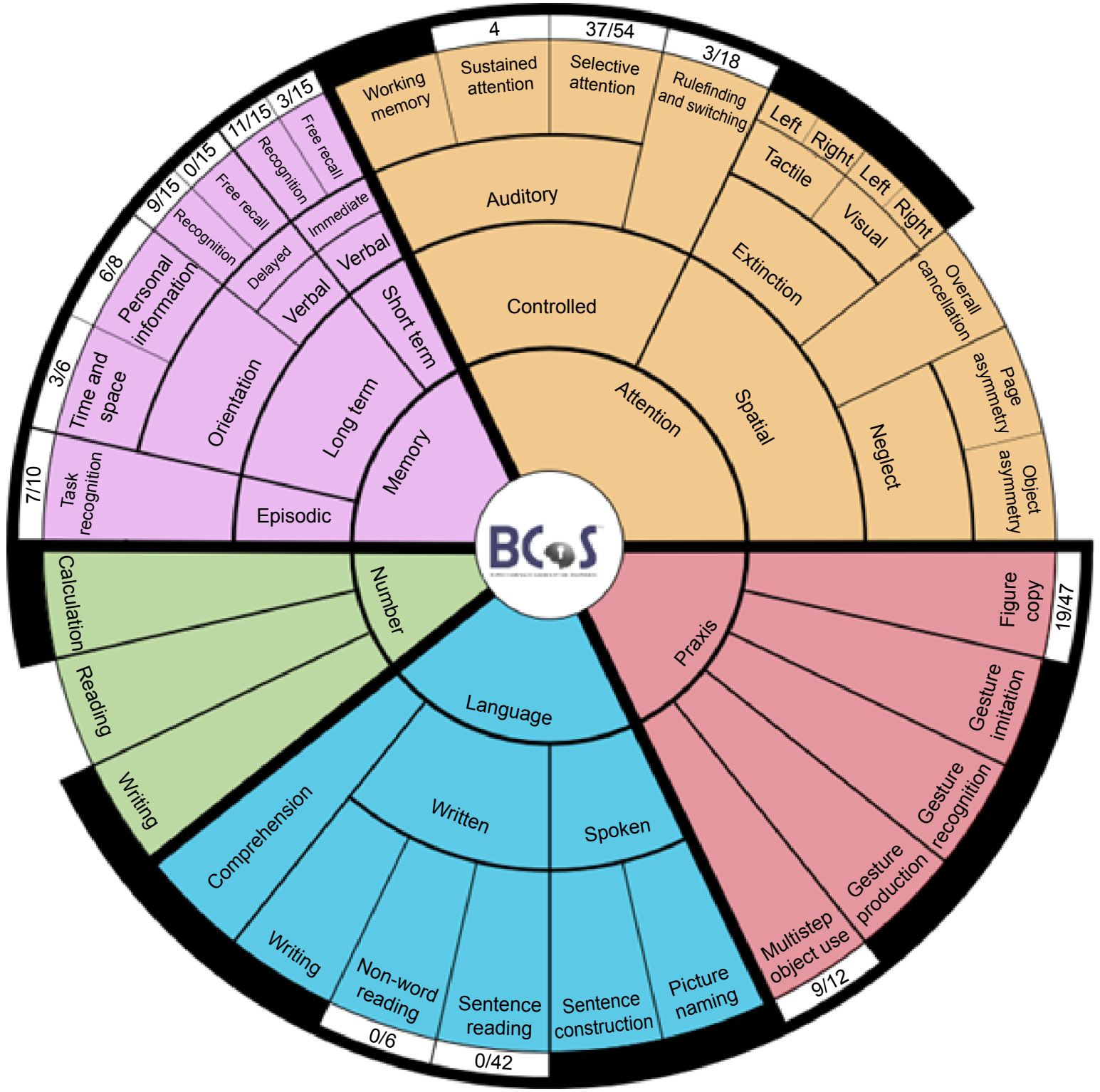

Figure SI Example "visual snapshot" of the cognitive profile of a patient given by the BCoS.

Notes: Each colored area represents a different cognitive domain. In the reporting system, a black rim indicates intact performance (within normal limits). The rim is colored white when a deficit occurs relative to the norm. The rim is omitted if the test has not been administered. After a little experience, clinical teams learned to "read" the profile efficiently, identifying the strengths (preserved cognitive abilities) and weaknesses (impairements relative to the controls) of particular patients.

Abbreviation: BCoS, Birmingham Cognitive Screen.

\section{Publish your work in this journal}

Neuropsychiatric Disease and Treatment is an international, peerreviewed journal of clinical therapeutics and pharmacology focusing on concise rapid reporting of clinical or pre-clinical studies on a range of neuropsychiatric and neurological disorders. This journal is indexed on PubMed Central, the 'PsycINFO' database and CAS, and is the official journal of The International Neuropsychiatric Association (INA). The manuscript management system is completely online and includes a very quick and fair peer-review system, which is all easy to use. Visit http://www.dovepress.com/testimonials.php to read real quotes from published authors. 